\title{
Introduction for GIS-supplement
}

\author{
Claudio Lamartina
}

Accepted: 22 April 2009/Published online: 13 May 2009

(C) Springer-Verlag 2009

\begin{abstract}
"In 1977 the Italian Group of Scoliosis Study (G.I.S.) was formed. The aim of this Association is to promote and encourage the study, prevention and cure of scoliosis and other spinal disorders. One year after its foundation G.I.S. held its first Reunion in Pisa under the chairmanship of Prof. P.G. Marchetti.

The subject chosen, namely the treatment of scoliosis with braces, was very wide and demanding ... The works presented at the G.I.S. Reunion will be collected and published annually. This is the first volume of a collection called "Progressi in Patologia Vertebrale" which will acknowledge the validity of the work carried out by the group and will be a stimulus and an aid to everyone who has the wellbeing of our patients at heart".
\end{abstract}

This is part of the preface written by Romolo Savini, the first G.I.S. chairman, in the first issue of the official G.I.S. journal, published by Aulo Gaggi Editore in Bologna in November 1979. "Progressi in Patologia Vertebrale" became in the last years "Il rachide_Italian Journal of spinal disorders" has carried on for more than 25 years. This is due to the wish to publish the best of the Italian scientific production in the field of spinal disorders. However, the necessity of publishing an edition in English in order to overcome the language barrier, which heavily penalises scientific magazine in languages other than English, is just as strong. Evidently, only a great international journal could and can guarantee the necessary international visibility and therefore in 2001 and in 2008, under the leadership of Max Aebi, Editor-in-Chief of European Spine Journal, the abstracts of the works presented at the annual Congress were published in ESJ. Finally in 2008, the big turning point: thanks once more to the indispensable help of Max Aebi, Editor-in-Chief, and Marek Szpalski, Deputy Editor for Supplements of European Spine Journal, this supplement, a collection of the best of the 2008 G.I.S. Congress, was born. It is a great privilege and a great satisfaction for us to have reached this goal. We wish to thank the G.I.S. Board and all the members for their enormous help in contributing with dedication to this supplement. Finally, special thanks go to Mrs. I. Zintel of the Editorial Office of European Spine Journal and C. Federici of "My Meeting".

Stefano Cervellati G.I.S. Chairman

Claudio Lamartina Chairman of the 2008 G.I.S. Congress

C. Lamartina $(\bowtie)$

Istituto Ortopedico Galeazzi, II Spine Surgery,

Via Riccardo Galeazzi, 4,

20161 Milan, Italy

e-mail: c.lamartina@chirurgiavertebrale.net 